\title{
Introduction to the Pécs Model Innovation in teaching Medical History Taking
}

\author{
Á. Koppán*, K. Eklicsné Lepenye*, R. Halász*, J. Sebők**, G.A. Molnár** \\ * Department of Languages for Specific Purposes, University of Pécs, Medical School, Hungary** Second \\ Department of Medicine, University of Pécs, Medical School, Hungary
}

\begin{abstract}
Among clinical skills, doctor-patient communication is considered a high priority in establishing the proper diagnosis. Therefore, our team at the Department of Languages for Specific Purposes at the University of Pécs, Medical School (UPMS) has designed an educational model to improve these fundamental skills. Our primary objective is to share these innovative practices with others.

Peer-tutoring history taking courses are offered to international students assisted by Hungarian senior students, as well as digitally available educational materials. The latter is based on authentic doctor-patient conversations (video-recordings in Hungarian) while acquiring the patient's history. Following video recording, EU standardized texts from A1 to B2 levels are implemented including task-based case studies and check-lists to ensure the use of authentic communication.

The scene for pilot experimentation is a university course with blended-learning methods; the video-recorded conversations are used in class, followed by hospital-based practice to promote motivation and increase cultural awareness.

Aligned with the current general orientation of modern linguistics, we believe context-based language courses may better prepare physicians for interviewing their patients in the 21st century.
\end{abstract}

Key words: communication skills, clinical skills, context-based history taking, peer-tutoring, blended learning, medical training in international programs

\section{Introduction}

Early acquisition of clinical skills plays a significant role in medical training. These skills involve history-taking, physical examination, diagnostic imaging techniques and additional clinical investigations, effective doctor-patient and staff communication with particular emphasis on team work (Abdulmohsen, 2007). Among all the above, communication skills are found to be the pre-requisite for proper diagnosis and treatment, resulting in successful care with optimal time-management.

In our model the focus is on improving communication skills in international programs. The University of Pécs, Medical School similarly to a number of European universities provides medical training in English and German languages. Although all the core professional subjects may be studied extensively in these languages, the early encounters of medical students and patients can only take place in an authentic setting through the language of the host country, in our case, Hungarian. Thus, clinical skills acquisition becomes an interdisciplinary field integrating professional and language skills. Earlier it was considered the weakest point of medical training in foreign languages: acquisition of history taking skills through language and intercultural barriers was questionable. Application of our model guarantees the desired results. Our program has a two-fold objective: first, to enable students to bridge the gap between the two fields, and solve language-related communication problems, which represents an inevitable part of quality medical training, and secondly to ease the burden of overloaded doctors by preparing students for history taking. 


\section{Methods}

Originally, the design of the model was developed on language and professional requirements analysis (Koppán, Halász 2014; Eklicsné, Koppán, Németh 2015). Interestingly, the evaluation revealed international students acquire Hungarian Language skills primarily as a tool implemented when taking a patient's past medical history, performing a patient examination (within a Hungarian hospital) and additionally, to support on-going professional training. In collaboration with clinicians we explored the medical field's needs, followed by updating the educational material. Once the relevant data has been accumulated, we began searching for superior methods meeting or exceeding today's generation of learning styles and characteristics.

Our model is based on two main methods: peer-tutoring and blended-learning. The former is discussed below, the latter incorporates classroom and mobile learning (based on videorecorded conversations and related exercises in an online environment). The innovative measure may be found in teaching history taking through medical Hungarian to international students who - assisted by Hungarian senior students - acquire medical communication with real patients in an authentic hospital environment developing valuable interviewing skills. These skills are further improved by viewing and assessing video-recorded doctor-patient dialogues in the classroom. In all earnest, we believe the Pécs Model is superbly innovative, as peer-tutoring is a rarely applied model in Hungarian higher education, particularly because it combines language and professional skills, enhancing its development and ensuring authentic real-time scenarios featuring genuine participants (hospital staff and patients).

\section{Peer-tutoring}

Since the1980's peer assistance in acquisition of clinical skills has achieved immense recognition and widely accepted, e.g., in Germany (Krautter et al, 2014) the University of Heidelberg, the model is called PAL (peer assisted learning). The university's senior medical students assist their junior university students in the studies of history-taking.

The English word 'peer' - in Hungarian literature - is also interpreted as 'fellow-sufferer'(Rácz 2008), highlighting the shared or mutual status between partners similar in age, which is a determining factor in building trust and genuine reliability. Effectively the work accomplished by peers is built on agreement and motivation to achieve a common goal.

The phenomenon of shared status is described in Boud's reciprocal peer learning (2001) highlighting the mutual benefit from studying together.

Similar to the above notion, Nestel and Kidd (2003) claim that peer learning is a key factor in improving clinical skills when taking past medical history with a patient-centered approach.

Gwee (2003) argues that peer learning, especially in small groups, nurtures and facilitates the development of self-directed learning skills, including critical thinking and problem-solving skills; communication, interpersonal and teamwork skills; and improves peer-assessment and critical reflection.

\section{Mobile learning}

Currently a responsive interface is being developed at our department towards engaging the requirements of updating practice materials and the immediate availability of the material on tablets and smart phones. Our website is designed to enhance motivation. All materials available are contemporary and regularly updated. 
Our website provides learning opportunities from the first year of studying Hungarian. During the early phase the focus is on the language preparation for history taking: vocabulary expansion, practicing grammar and pronunciation. In the second year, the emphasis shifts to listening comprehension skills, situational awareness dialogue based on authentic doctorpatient dialogues and routine questions in the field of internal medicine become more emphasized.

Films provide the basis for educational materials including periodical examinations and testing: the purpose is to enable students to follow the examples and accomplish a history taking task at their particular level. This has been initiated during the first year with sustained attention and practice into the second year.

Video-recording has a designed system:

Films thematically follow the modules of our medical training with focus on internal medicine as a basic field, then further specialties. There is a collaboration of clinicians and language teachers; clinicians collect data of typical diseases in the field, then within each module our recordings are based on those typical diseases. The scenario is history taking (the doctor asks questions about the past medical and social conditions, and present illness of the patient followed by physical examination). Recordings are assessed and processed (formation of didactic patient's answers).

Level 1 - actors - wide spectrum of simplified responses

Level 2 - actors

Level 3 - original recording

Linguistic processing also includes patients' answers in reference to common misunderstanding. Doctors' questions are not modified; however, we apply a communicative approach. In the exercises designed for the films we focus on interviewing strategies, linguistic tools of politeness and emphasis, comprehension markers and the structure of the conversation (rigid structure, constant repetition, and establishing new subtopics) beside traditional language teaching vocabulary expansion and other exercises.

Following classroom activities, mobile learning tools convert the study material and are readily available for rehearsing for history taking within the sphere of peer learning.

Video-recording serves a double function. One is providing authentic models by the real doctor-patient conversations that enable development of clinical skills including interviewing techniques, patient examination, making diagnosis and writing case histories. The other is improving self-assessment skills and enhancing professional performance and delivery through reviewing the recorded doctor-patient dialogue and interviews. We have started to integrate this application of the videos into our curriculum as a test pilot program; however, due to constant updating and revising, an additional semester is required to ensure stable accessibility for the majority of our students.

Login interface for interviewing patient in the peer-tutoring /Tandem design is ensured for both international and Hungarian students.

\section{Training tutors}

It is of the utmost importance to motivate potential future tutors, senior Hungarian students, who already possess professional skills to acquire the necessary assisting behavior to comprehend how they can help their peers with the language and communication needs. It is also a learning process for them; since commenting and correcting one another's grammar and communication mistakes may appear to be harsh or negative criticism by its nature, but it should be understood the goal intends the complete opposite and as a result, is immensely beneficial to the participating and willing students. 
To determine a method and the proper opportunity towards effective interruption requires confidence, developed communication skills and empathy.

\section{Results and Discussion}

Currently, the innovative program demonstrates measurable success as a result of its popularity among students who wish to join this type of education in a growing number for its motivating power, and is also deemed effective by the University's senior leadership. The former communicative means of education is today replaced by the authentic doctor-patient dialogue and communication resulting in live interview with patients assigned to the clinical ward.

International and Hungarian students practice and develop medical language competencies while taking the patient's medical history together. The junior international student is assisted by not only a language but a professional tutor - a senior Hungarian student- who assists in structuring and sequencing pertinent medical questions to meet the professional protocol promoting assessment and detailing the final diagnosis.

To the senior Hungarian student tutoring conversations is considered to be invaluable both from a professional and communicative perspective: doctor-patient communication is taught in the first year of the medical training with little or no opportunity to evaluate patients, and the students are heavily involved towards absolving the core subjects, i.e., anatomy and physiology. Without successfully navigating these principle subjects, medical communication cannot possess a significant role.

Within the students' curriculum, clinical subjects are present from the third year similarly to the English and the German programs, providing the opportunity to actively engage the patients at bedside, and acquire essential skills of interviewing patients and performing physical examinations. Unfortunately, the first-year doctor-patient communication courses are largely forgotten over time; therefore, the fundamental conversational techniques should be acquired within the frames of the clinical subjects. The difficulty arises from the lack of time and opportunity for practicing the interviewing skills during clinical practices. Suitably, this is the ideal time towards developing deep interest in the medical profession, empathy toward the patients, and awareness of the patient-centered medicine.

Extracurricular activities - tutoring international students during bedside history taking enable the Hungarian medics to effectively prepare for their future career and become a good doctor. Soon enough, they realize the well-structured doctor-patient interview ideally ensures an appropriate diagnosis and adequate treatment. The previously mentioned peer-tutoring in history-taking groups provides an ideal opportunity for professional practice while internalizing the procedure of interviewing the patient. They must explain 'what, how and why in the specific measure we inquire in Hungarian' to the international students many times. Meanwhile, they develop and personalize their professional delivery of standard and routine questions paving the way to more effective and valued conversation.

The comparative analysis of the two languages is inevitable, as well as the exploration of differences and similarities between the cultures and history taking strategies of the medical students alike. Internalization of the above is of high importance for both the Hungarian and international students, hence more and more students start and accomplish their medical studies in Hungary, so the principles of doctor-patient communication are acquired at our university. This immense responsibility empowers us, colleagues of languages for specific purposes, to engage and prepare the students for history taking and language related physical 
examination, at the same time to increase awareness of doctor-patient interviews in their own languages and also Hungarian.

Beside oral communication, written skills are also improved, as case histories should be written by the students based on their notes taken at the clinic. Patient bedside interviewing is followed by an in-class processing where students are paired off to discuss and assess the information collected from the patients. Afterwards, there is a plenary format presentation session where they summarize the experience of the conversation, the patient's attitude, willingness to cooperate, interesting data and a possible diagnosis.

Reconstruction of the dialogues and case histories happens at home also in a written format in the target language (in Hungarian for the international students, in German or English for the Hungarian students), followed by correction of each-other's work, commenting mistakes via e-mail or social media. The final result is sent to the teacher, who forwards the collected case histories to the clinician for assessment. Thus, the course integrating peer-assisted learning contributes to practicing oral and written communication and professional competences.

\section{Conclusions}

We believe that the Pécs Model successfully contributes to previous teaching LSP (Language for Specific Purposes) approaches, which state first and foremost, general language is taught extensively and then followed by the specific language. Medical trainings need measureable results (being able to take medical history) in a limited time. Thus, following a brief general language course, the students are immersed into the LSP instruction, focusing on situational communication required by the professional settings and guidelines.

Our model is based on permanent needs analysis, aiming to explore all the components of LSP skills collected, and provides the basis for designing and implementing valued curricula. The pioneer German majors (colleagues of the Pécs Model) attend clinical courses combined with the international students in varied courses such as internal medicine, cardiology, dermatology and neurology to collect information of their professional needs. (In the following year vast amounts of data are collected and plans strategized for their future implementation).

The development of communication skills is a crucial area of focus for Clinical Skills Labs (CSLs). More and more universities establish CSLs for their substantial support of education. In fact, a better name for those laboratories would be clinical and communication skills centers or units, because the proper application of clinical skills requires the integration of technical clinical skills and those of communication (Kneebone et al, 2002).

A modern Skills Lab meeting the $21^{\text {st }}$ century requirements will soon open at the University of Pécs, Medical School. In the near future we hope to begin teaching techniques of historytaking in its communication skills lab. Ideally, it will provide the necessary environment for the innovative teaching-learning model integrating students of the three language programs at our respected university.

\section{References}

Abdulmohsen H. Al-Elq. (2007) Medicine and Clinical Skills Laboratories

In: J Family Community Med. May-Aug; 14(2): 59-63.

http://www.ncbi.nlm.nih.gov/pmc/articles/PMC3410147/ 
Boud, D. (2001) 'Introduction: Making the Move to Peer Learning'. In Boud, D., Cohen, Ruth \& Sampson, Jane (Ed.). Peer Learning in Higher Education: Learning From \& With Each Other. London: Kogan Page Ltd,1-17.

Gwee C.E.M. (2003) Peer Learning: Enhancing Student Learner Outcomes. CDTL 13.

Eklicsné L. K, Koppán Á, Németh T. (2015) How to involve medical history taking effectively in LSP teaching. Presentation given at the Language Centres in Higher Education: Sharing Innovations, Research, Methodology and Best Practices Conference in Brno, 15-17 January 2015, will be published in the CASALC Review.

Halász R, Koppán Á. (2014) A magyar orvosi kommunikatív szaknyelvi kompetenciafejlesztés lehetőségeinek vizsgálata a szaknyelvhasználati szükségletek és a tanulási szituáció feltérképezése alapján.In: Bocz, Zs. ( Ed.) (2014): PORTA LINGUA 2014 (pp.311-318)

Krautter M, Andreesen S, Köhl-Hackert N, Hoffmann K, Herzog W, Nikendei C. (2014) Cross-year peer tutoring on internal medicine wards: results of a qualitative focus group analysis. Advances in Medical Education and Practice. 5:323-330.

Kneebone R, Kidd J, Nestel D, Asvall S, Paraskeva P, Darzi A. (2002) An innovative model for teaching and learning clinical procedures. Medical Education. 36:628-634.

Rácz J.(szerk.) (2008) Az esélyteremtés útjai: kortárs és sorstárs segítéssel szerzett tapasztalataink. 12-108. Budapest, L’Harmattan Kiadó.

http://www.edutopia.org/pdfs/guides/edutopia-mobile-learning-guide.pdf 